Meta

Journal des tradlucteurs

Translators' Journal

\title{
A Poet in Search of a Medium? An Analysis of the Graphological Structure of Taban Lo Liyong's Another Nigger Dead
}

\section{Ogo A. Ofuani}

Volume 34, numéro 2, juin 1989

URI : https://id.erudit.org/iderudit/003755ar

DOI : https://doi.org/10.7202/003755ar

Aller au sommaire du numéro

Éditeur(s)

Les Presses de l'Université de Montréal

ISSN

0026-0452 (imprimé)

1492-1421 (numérique)

Découvrir la revue

Citer cet article

Ofuani, O. A. (1989). A Poet in Search of a Medium? An Analysis of the

Graphological Structure of Taban Lo Liyong's Another Nigger Dead. Meta, 34(2),

225-237. https://doi.org/10.7202/003755ar d'utilisation que vous pouvez consulter en ligne. 


\section{A POET IN SEARCH OF A MEDIUM? AN ANALYSIS OF THE GRAPHOLOGICAL STRUCTURE OF TABAN LO LIYONG'S ANOTHER NIGGER DEAD 1}

Ogo A. OfuaNI

University of Benin, Benin City, Nigeria

I - The relationship of a language user to his medium may be seen initially as the simple one of which he is using, of whether he is speaking or writing. The proposal by Gregory is that the medium relationship of writing be sub-categorized in terms of the degree of orientation of the writing towards the possible speaking of it. ${ }^{2}$ This is not in itself to suggest that writing is derived from speech, to assert any causal relationship of that sort between the media; it is to maintain that in literate societies all that is written can and may be spoken and that in literate societies all that is written can and may be spoken and that a considerable, perhaps increasing proportion of such language has the speaking of it definitely in mind; and the converse is not so true, that except when dictating we rarely speak with the writing of what we have spoken in mind.

In his categorisation of speech and writing, Gregory included poetry within a large group of "written to be spoken." He tried to distinguish between two kinds of poetry: in non-literate and literate societies. In non-literate societies, poems are recited, technically meaning that they involve the speaking of the poetic texts, non-spontaneously, such texts "written down" in the memory of the reciter, as it were. In literate societies, poetry is written to be spoken. If this sub-division is pursued further, we find ourselves immersed in the controversy about which medium is primary, speech or writing? The implication of the dual categorisation is that, at one level, speech is primary (the written text is secondary and dependent upon speech in writing) and that at another, writing is primary and is aimed at speech.

Levenston has also observed that the desire to see poetry as primarily either written or spoken may derive from our everyday experience of language. ${ }^{3}$ Or rather from the way we tend to think about it. We are accustomed to regarding the two media, speech and writing, as functioning independently. Thus because of the predominantly written form of poetic texts in literate cultures, the tendency has been for poets and critics to see the written text as primary. But this conventional stereotyped view of the difference between speech and writing is clearly an oversimplification. The continuous deliberation of speech and writing supremacy in poetry will not aid a resolution of the debate since it is obvious that poetry has a dual existence (when it is seen to exist simultaneously as both speech and writing, with neither primary but both of equal status), a dual existence which is not sequential, one deriving from the other, but simultaneous. Poetry seems therefore to be essentially both written and spoken. (There is some kind of sequence here, in the speechwriting relationship as far as literary genres are concerned, with poetry and drama having phonic potential.) As Levenston has further observed: 
It has been assumed that poetry exists in a world of speech and writing. This assumption is largely justified as far as Western tradition is concerned. It only breaks down when we broaden our conception of poetry to include oral performance in non-literate societies. ${ }^{4}$

This observation is valid for the discussion that follows because it reveals that there are other possibilities to be considered. What, for instance, is the pattern to be adopted by the African writer, caught as it is, in the web of Western literate tradition but who is very much part of his immediate background, its poetic forms and devices? The East African experience, particularly in the case of Okot p'Bitek who just writes in Acoli and later translates to English (Song of Lawino, 1966) is, like his forebears, based on the belief that poetry is oral and is to be "performed." It is obvious in the work of Kofi Awoonor'. Taban lo Liyong has also had his share of documenting songs and stories from his own background. ${ }^{7}$ What, then, is Taban lo Liyong's idea or feeling about the poet? What does he say about his poetic form? Are the deviations in form observed in Another Nigger Dead more of his own way of expressing his art than as faulty deviance from the expected norm - more of his uniqueness? Can he not use the graphic form of the Western tradition by putting his poems on paper where his ancestors had depended on memory for record-keeping, and, at the same time, modify this alien medium to give the purely phonic substance of his background, such that the "middling" hybrid (in Another Nigger Dead) is what we have: where stanzas, verse-lines are Western conventions, and the traditional element surfaces in the non-use of punctuation to create the illusion of speech ? Is it not possible that he conceives of such punctuation marks as merely artificial, postspeech (or extra-speech) conventions? These conjectures will, as shown below, throw some light on his peculiar poetic conventions in his use of the graphic medium in his collection.

II - Criticisms of Taban lo Liyong's poetic form, particularly in Another Nigger Dead, have tended to totally disregard or to cursorily gloss over the peculiar nature of the typographic / graphological shape of his poems and their significance. They tend to dismiss it as merely incidental and non-functional. For example, Adrian Roscoe sees him as an "eccentric" and concludes that his use of "lower case letters without punctuation" is merely "curious"8. He does not seem to consider the possibility of the poet using the lower case letters in Another Nigger Dead for significant stylistic effects since he had earlier on in Frantz Fanon's Uneven Ribs been a lot more consistently conventional in the use of the forms which he now openly and constantly deviates from. Roscoe is not alone in this "literary" trend. They also appear in varying degrees in the work of other critics, in the form of general and sweeping remarks about Taban's form. ${ }^{9}$ For example, Wangusa says that:

In form and expression he is among the very "freest" verse writers, defying all rules and guides. And yet a central preoccupation of his poetry is that of the very nature of poetry. 10

Recognizing Taban's "preoccupation" with the nature of poetry is one thing, but realising that this preoccupation may be responsible for his own actual practice of the art, in his use of medium, and that he expects his use of medium to be taken seriously, is another. Jones not only considers thematic issues but mentions the linguistic significance of the medium. To him, ideas, "sometimes straight, sometimes ironic, humorous, serious, parallel, contrasting, are massed together to produce a prickly, jumpy effect" in Another Nigger Dead."1 About his graphological deviation, he observes that "for the eye alone the poetry seems to flow, but for everything else ... lack of punctuation slows down comprehension." This suggests that lo Liyong's non-use of punctuation is more of an unnecessary nuisance, not significant and functional but rather obscuring. 
This paper will therefore attempt to trace a relationship between Taban lo Liyong's conscious graphological deviation in Another Nigger Dead and his conception of poetic art, particularly the significance that he seems to attach to this process. In the earlier Frantz Fanon's Uneven Ribs, ${ }^{12}$ he was more conventional, on the average, as far as the "canonical" aspects of poetic form are concerned. For example, he uses verse-lines, stanzas, capitalisation, punctuation and free verse. A very large proportion of the poems in that collection conform to conventional patterns, and if compared with Another Nigger Dead will seem experimental, particularly in the sense that the "new" poot in that collection was almost merely conformist, has not yet "found his feet" and seemed unsure about how much to differ. But if one considers the thematic fact that he was obsessed with deciphering or giving form to his poetic art in that volume, one is not too wrong to insist that he was experimental. He says, for example, in "The Best Poets,"

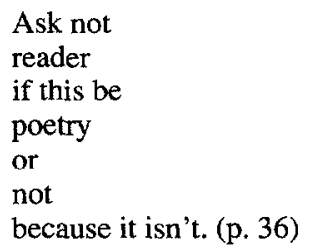

He re-echoes this thought in "The Throbbing of a Pregnant Cloud" when he observes:

Times have changed

Prose in poetry now

Perhaps thoughts are now poetry

And weather prattle

Prose (p. 25)

Taban dismisses poetry because "nobody speaks" it; its thoughts are arranged unnaturally ("Best Poets"). But prose is too wordy and time-consuming for the reader, and Taban will offer something in-between, which looks like poetry but is not. It is simply a mosaic made up of single thoughts set out simply:

I would be dead before

poetry rule-full I learn. (p. 38)

This atmosphere of doubt seems to be present in almost all the serious poems of Frantz Fanon's Uneven Ribs. In Section IX of "The Throbbing of a Pregnant Cloud, he even thinks that he is a "poetaster," an experimenter, an apprentice, merely poeticising :

Don't be mad man

All this is prose

Plain plain old prose

You are not suited to poetry

Perhaps you are a poetaster

But really man this is prose stuff

And prose it is man. (p. 25)

His reasons for feeling this way, for feeling disenchanted with both poetry in its conventional form and with prose, may not be too remote to find, for in the same collection he observes in "The Best Poets" that 


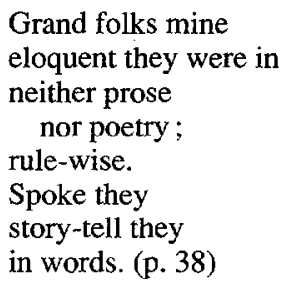

There is no doubt therefore that there is the strong urge for him to speak in his poems, in not sounding "poetic," in drawing closer to the colloquial ranges of the English language. This is obvious in the preponderance of the indexical markers of conversational speech one finds in his poems: clipped forms ("Don't," "that's," "I've," etc.), intimacy signals such as "man" in "Don't be mad man" above, even the very familiar tone of the poem. One wonders, therefore, whether his quest for a purely authentic and personal poetic form is responsible for the experimentation, in the "breaking of the rules" in some of his most formally different poems in the book, especially "Uncle Tom's Black Humour" and in the first part of "To Susan Sontag, With Love." In the two poems, and in others, personal pronouns, line beginnings, proper nouns, are not capitalised and punctuation marks are completely left out. The only capital letters used are bold-type characters in words which are made to visually stand out as some kind of poetic "shouting voice." For emphasis, in the midst of lower-case letters, viz:

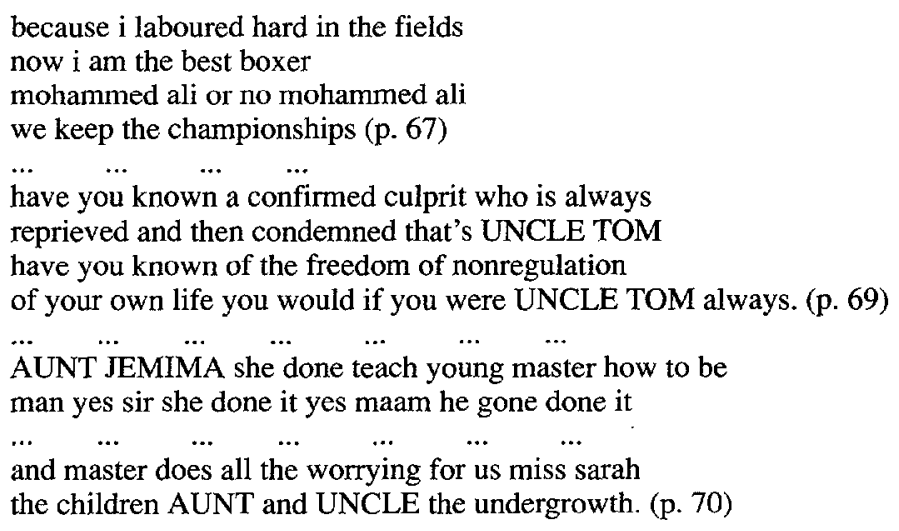

The answer seems therefore to be that this initial experimentation in "canonical" deviation in Frantz Fanon's Uneven Ribs, as far as the quest for a Tabanic poetic voice and form are concerned, seems settled, with some finality of purpose and determination, in Another Nigger Dead. Hence he advises us in "The Best Poets":

Call it

What you may.

Digestible

bit by bit

my thoughts I present

read on. (p. 38)

III - A discussion of the significance of deviation in Another Nigger Dead ${ }^{13}$ may be related to the issue of Taban's quest for an appropriate medium and form. His poems are primarily written, but give the impression, on being read, that he intends that they be 
"read as if spoken" or even "as if the poetic voice is being actually heard or overheard," depending on what poem is being considered. The latter view may find support in the consistently single narrative voice of the poetic character in all the poems as if he is involved in some kind of personal soliloquy or monologue, or even the chatty familiar conversational tone most of them acquire. The following illustrates this :

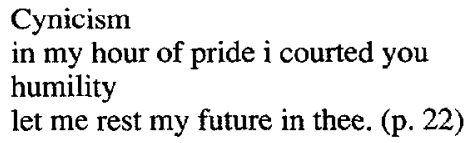

"Cynicism" and "humility" are obviously abstract entities but the poetic voice addresses them as if they are real and tangible, almost human: he personalizes them in the use of the second person singular pronouns "you" and "thee." But, obviously, he is only involved in a kind of meditation or reflection. His folly and pride in courting cynicism in the first two lines is balanced by his search for humility in the last two lines. The single narrative voice effect mentioned is also noticed in the predominant use of the personal pronoun "I" in narrating all the experiences and feelings.

How then does the poet see his art in terms of the speech-writing dichotomy? Does he see his poems, though written, as to be primarily spoken, therefore implying that there is no use for "obeying" the purely poetic conventions of the graphic form in English? Could this illusion of speech be responsible for the graphological shape of the poems? If the thoughts of conventional poetry are unnaturally arranged and prose is too wordy and time-consuming for the reader, and Taban wishes to offer something in-between which looks like poetry but is not, could this new pattern not be his compromise? Does he see the formal patterning of sentences in English as merely formal, unrealizable, abstract and thereby unnecessary in poetry, the actually realizable patterns being utterances, stretches of sound-meaning relations where punctuation is rather artificial and unimportant? One strongly suspects the influence of oral traditional poetry on the shape of the written form of lo Liyong's poems, especially in determining what a verse-line should be. If these conjectures are true, then the graphological deviations are used to bring his poems nearer to the spoken mode.

S. R. Levin has identified two groups of deviations in poetry: those produced against the background of the language, and those produced against the conventions of the poem as a literary genre. ${ }^{14}$ Deviations of the latter sort take many forms, as there are many conventions. Thus, the metre may be deviated from; a form may be deviated from, e.g. the sonnet form; a rhyme-scheme may be deviated from; one may deviate from the conventions of beginning the lines of a poem with capital letters, as two American poets, William Carls and E. E. Cummings do consistently; the convention that a poem should employ a certain "poetic" diction may be deviated from, etc. But he concluded that as interesting as the study of the above deviations may be, "it is ultimately not the proper concern of linguists; it devolves rather upon students of literary form to investigate and to point out the significance of such canonical deviations." 15 It is our contention here that these are not only the concern of the literary critic but also of the stylistician, "whose intention is to bring linguistic theory and methodology to bear on specific literary problems," as long as these forms are foregrounded by the poet with the aim of giving them prominence, making them significant. ${ }^{16}$ Levin, however, agrees with this in a later paper when he says that

... deviation in poetry is an attribute of form. And because deviation is an attribute of form, the interest in responding to it, attaches only secondarily to what the deviant expression is saying, but immediately the expression itself. It is this characteristic of a deviant expression. 
that of calling attention to itself as object, which gives it its importance in stylistic analysis. And it is this same characteristic that prompts the consistent and sustained use of such expression in poetry. 17

By analogy, the same could therefore be said of these canonical deviations as being the concern of the stylistician if they draw attention to themselves. The graphological deviations of Taban's poems in Another Nigger Dead are clearly attention-drawing and therefore intended to be significant. We notice it because we have various expectancies about the nature of poetry.

The key example of this might seem too obvious to mention: it is the characteristic line-by-line arrangement of poetry on the printed page, with irregular right-hand margins. It is our expectation that the beginnings and ends of lines of poetry do not occur at the margins of the page, but wherever the poet means them to occur, with the result that a poem may have irregular margins. In the same way, breaks in the thematic progress of a poem are indicated not by indentations, but spacing, and one speaks of stanzas, not paragraphs. ${ }^{18}$ In poetry, these patterns are normal, expected, but deviant in the sense that they deviate from the norms of ordinary-language typographical practice. The typographical line of poetry, like the typographical stanza, is "a unit which is not paralleled in nonpoetic varieties of English; it is independent of, and capable of interacting with, the standard units of punctuation. This interaction is a special communicative resource of poetry."19 In this case, we can say that most of the poems in Another Nigger Dead are conventional. They are arranged in stanzas, particularly the longer poems at the beginning and end of the book, but some "internal" deviance from this poetic convention is noticed in the spacing of the lines from the margins. For example, the first two stanzas of the first poem, "bless the african coups" (p.1), have lines arranged in a straight line from the margin:

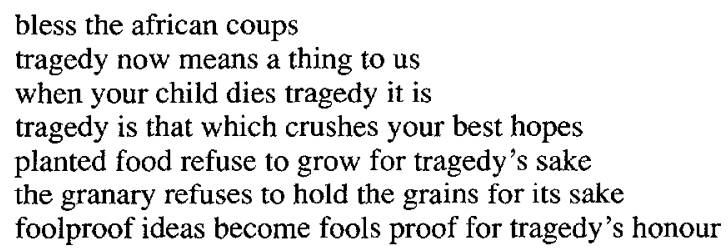

This arrangement is maintained in the majority of the poems in the book (118 out of the 123 poems in the collection). But in the third stanza, as the thematic confusion of the coups and Africa's tragedy are enumerated, the pattern is broken and the arrangement of the lines becomes alternately irregular (thereby revealing some regularity in this irregular but steady pattern that reminds one of the "left-right," "left-right" movement of soldiers' feet, the initiators of coups and therefore of Africa's habitual tragedy):

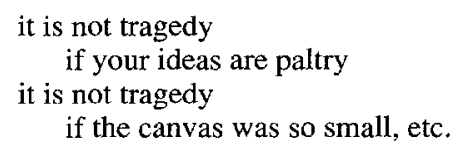

This apparently staccato pattern in the arrangement of the lines, underlying the confusion and tragedy in Africa as "tragedy" is retained as the key-word, maintains a choral pattern, in the poem, a choral pattern of ironic statements that too clearly emphasizes that tragedy is ALL that the poet says it is not. The same form is kept in the last two long poems at the end ("when some people dig with hoes and others with tractors" and "heres something 
ive always wanted to talk about"), with the exception of the dream-land prose passage, "Batsiary in Sanigraland." The verse-line arrangement may not seem too significant an aspect of poetic language but serves as a foregrounding element, for drawing attention to the poems and so is meant to be taken seriously.

The kind of deviation observed in the arrangement of lines is also characteristic of the stanzaic pattern of the poems. Only the two long poems at each of the beginning and end of the collection are of irregular lengths and arrangements. The other poems forming the middle of the collection are single-stanza poems, also of varying lengths and patterns. They are all however so textually cohesive, especially in the repeated use of the personal pronoun "I" and all its other variants, that one tends to agree with Roscoe's assessment that "every stanza is listed as a poem," suggesting that the collection is a single poem, a simple experience (made up of different movements of meditations), Taban's. 20 The significance of the stanzaic pattern of the poem seems however, to lie in the fact that inbetween the long poems, forming the premise and end of the argument of the collection, are scattered recollections of the poet. They came as quickly as the collections are diverse that they are stated as they are, as if the poet hurriedly set them down on paper before he forgot. 21 This is bolstered by the epigrammatic, proverb-like quality reflected in these single short-stanza poems. Their significance lies in their mnemonic features (features aimed at ease in remembering).

The grammatical structure of these short-stanza poems also aids in this direction. The extra-ordinary cohesiveness of the syntactic structure-repetition of clauses of the same structure, repetition of nominal groups that have an equal number of syllables, the repetition of verb-types, especially in their morphological shape, the cohesive nature of the personal pronouns "I" and "mine" that make the experience personal - make them so memorable and emphatic that the epigrammatic quality mentioned is underscored. The total significance is that after initially lamenting African tragedy in the first two long poems, he remembers scattered, innumerable instances of the African tragedy not remembered in the first two poems. (They connect thematically with the title of the collection, deriving from the first poem.) The poet does not want the reader to forget easily.

The analysis of the syntactic structure of the poem "building a life philosophy" (p. 36) will suffice as an example.22 The poem has four lines:

$\begin{array}{ll}\text { building a life philosophy } & 1 \\ \text { through juggling with words } & 2 \\ \text { fashioning home truths } & 3 \\ \text { by exploring the obscure } & 4\end{array}$

The first observable feature of the poem above is that the poet either assumes some exophoric knowledge on the part of the reader or he takes it for granted - he does not supply the subject(s) of the verbs used in the lines. This lack of a specific subject makes the experience almost universal since the theme of the poem - futility in literary creativity - may apply equally to both the poet-speaker and to the reader (as a kind of generalisation). With the omission of the subject (S) component of the clauses, what we have are two almost balanced clauses of the PCA (Predicator, Complement, Adjunct) structure, the first two lines making up a clause and the last two lines another clause. They are paratactic in the sense that unless the missing subject is implied, the clauses are left detached. 'They can be rearranged as follows to show the balance:

(i) building a life philosophy/through juggling with words

(ii) fashioning home truths/by exploring the obscure. 
At the clause level, the Predicator is made up of verbs of the -ing present progressive form ("building," "fashioning," "juggling," "exploring"), showing that the actions described are on-going. The direct complements of the verbs, the $\mathrm{C}$ components, are made up of the two nominal groups of almost the same structure ("a life's philosophy" $=\mathrm{m} \mathrm{m} \mathrm{h}$; "home truths" $\mathrm{m} \mathrm{h}$ ) without qualifiers ${ }^{23}$; the Adjunct (A) components are made up of prepositional word groups made up of a preposition acting as connective ("through," "by") and the completive elements themselves are rank-shifted clauses of PA and PC structures, respectively ("juggling with words" ; "exploring the obscure"). At another level of delicacy, the A component contains verbs of the progressive kind while the other parts contain nominals performing different functions. So there is a balance in terms of the constituent structure at any one level of delicacy and this kind of regularity in the repetition of patterns characterises the poems in Another Nigger Dead. Consequently, there is a great deal of textual cohesion in these rather simple paratactic structures, not only at the individual poem level but also at the level of the other poems taken together. As said earlier, this feature gives the lines an easy-to-remember facility. The phenomenon of cohesion in literature obviously has everything to do with the fact that literature is art, that literary texts are constructed to produce in us the kinds of experiences we speak of as "aesthetic," in which symmetry or interplay of sameness and difference play a major role. It is therefore foregrounded for this special effect.

A more interesting typographic convention of poetry, one in which both internal and external deviation may be produced, governs the use of line-initial capitals. In the work of Taban lo Liyong under consideration, this particular convention is not observed. His convention, like that of E. E. Cummings, is to use lower-case initial letters, irrespective of whether the initial word marks the beginning of a sentence. This pattern pervades the whole collection, with the exception of the prose of "Batsiary in Sanigraland" and poems like "bless the african coups" and "the filed man laughed and said" where capitals are used in the midst of lower-case letters in groups like "ANOTHER NIGGER DEAD" and "POVERTY" in the two poems, respectively, as further instances of the visual effect of bold capitals to mark the "poetic shouting voice" shown to have been earlier used in Frantz Fanon's Uneven Ribs (especially in "Uncle Tom's Black Humour"). This practice presents a deviation not only from the poetic convention but also from the external norm of ordinary language usage, from which poetic language is expected to deviate in the first instance. He goes further and differs from E. E. Cummings in the total "disregard" of every other punctuation mark: commas, full-stops, semi-colons, apostrophes, exclamation marks, etc. He does not, however, go the extent Cummings goes in his rather unusual usage of the morphological process of English in deriving words like "unwish," "manunkind" and "unself" as in the poem "pity this busy monster, manunkind" 24 .

Cummings does not start the lines of that poem with capital letters but uses all kinds of punctuation marks which Taban lo Liyong avoids. Their poems exhibit about the same degree of eccentricity but this aspect of Taban's poetic form seems to have been responsible for the evolution of what Chris Wanjala (1971) has referred to as "the Tabanic genre," a genre he dismisses too easily as "indisciplined."25 But in spite of Wanjala's assessment, in spite of the unconventional use of punctuation marks (or the lack of use of punctuation), some order, cohesion, has been shown to exist in the "disordered" pattern to allow him (Taban) the credit of some artistry / art. This feature of Taban lo Liyongs's genre is significant because it has certain stylistic effects discussed shortly, despite the fact that the poems, at first glance, look like exercises for practice on punctuation, as illustrated by the extracts below: 
(1) free lance critics circumscribe perimetres consign to gehenna and posterity what an elusive age no homer prize distributed. (p. 21)

(2) the african coup is an old beast insecure under rugs Youngsters with short memory wheres the future (p, 23)

(3) i dont drink with harry call me no misanthrope father saw my loneliness gave me brothers to keep (p. 44)

(4) not pride but glorification of my maker makes me use my talents for what they are worth ive clowned enough (p. 44)

These poems exemplify in various forms the different punctuation marks not used. They include the non-use of capital letters for proper nouns and for the first person singular pronoun: "gehenna" (Gehenna), "homer" (Homer), "african" (African), "harry" (Harry), and " $i$ " (I); the neglect of periods at the end of lines or at the end of sentences; the lack of apostrophe marks in the numerous contracted, clipped colloquial forms such as "dont" (don't), "ive" (I've), "wheres" (where's), etc. Further instances of such deviations abound in the collection.

IV - The contention here is that these graphological deviations are not merely cosmetic. If the poet intends that the poems "he read as if spoken," without providing the graphic signals that act reasonably as phonological cues for reading in English, then the options are left open to the reader to make whatever meanings he wishes out of them. In some of the poems, the reader can successfully use his intuitive knowledge of the expected patterns of English forms to predict where the punctuation marks should be applied to give a "correct" reading to the poems. Such predictive powers, which can be applied to the stanzas in the section above, include, for example, our intuitive recognition of an interrogative structure if there is a wh-question pattern ("wheres...," "what...") or the inverted verb + Noun question pattern, and the use of the appropriate intonational cues irrespective of lack of punctuation. But in some other poems, the poet may have intended some other effects. The unsuspecting reader may initially misread the form of a word (or words) as they are presented in the text before realizing that his inference may be wrong. $\mathrm{He}$, therefore, re-reads the poems. Meanwhile, the initial reading and interpretation is not discarded, likely suggesting to the literary interpreter that the poet may have intended to cause ambiguity, through punning, by leaving the word in its present shape. The ambiguous word or structure may therefore have to be disambiguated in various ways, particularly via phonological devices (use of prosodic features to supply caesura, end-stops, enjambment, etc.), after visually "supplying" the missing punctuation marks. This may slow down the reading speed, therefore enforcing that the reader take time to ponder and debate the possibilities suggested. This way, the non-punctuated forms are being foregrounded. 
One kind of ambiguity caused by typographic deviations of the above types is lexical. What would normally be interpreted as more than a word may, because of its present homographic shape, be given an equally homophonic reading. The poem "there goes my son" (p. 11) provides a good example. A cursory reading leaves the impression that Taban lo Liyong is, thematically, exhorting bourgeois qualities in the poem. This will be due to a reader's failure to allow for possible irony in the poem. The first four lines of the poem convey this tone of exhortation which somehow is intended to be ironic, but the irony is indirect, not through the tone of the persona but through the contrast between what is expected by the poor, trampled people and what the persona expects:

1 there goes my son

2 a bright lad doing well at school

3 my heart flows with honey when people remark

4 hell be as successful as his daddy

There is an unmistakable conspiratorial tone of voice giving the impression that the persona expects the reader to take his side. But the unpunctuated "hell" in the fourth line is ambiguous. The first urge is to read the form visually as HELL (the Biblical inferno, which should collocate with Satan / Devil). But the unsuitable collocation of "hell" in the context of "successful" (syntagmatically) immediately strikes a warning that there is either a misreading or a wrong collocation (for deliberate functions - an instance of poetic licence). This reading has a further possibility, which, though farfetched, will find support in the rest of the poem. The poet, without using punctuation, and in spite of the fact that he pretends to be the narrator, uses direct speech with some lines used as narrative tags. The line "hell be as successful as his daddy" is obviously what "people remark" (in line 3). There should have been an end-pause marked by either a comma or a colon after "remark." But since punctuation marks are missing, the line can be read as follows (i.e., if the marks are added): "Hell! Be as successful as his daddy!", where "hell" will be a swear-word (a sign of the people's infuriation in the context of a poem, in a sentence whose structure has more in consonance with speech expected of the lower classes). This declarative tone is obvious in other lines in the poem:

(i) others will say / his father was the best hunter with spears (5-6)

(ii) others will envy / brought up well at home (8-9)

But when one realizes that the ambiguous form in line 4 is to be read, on the other hand, as "he'll" (the contracted form of "he will"), the initial effect registers the contrast between the contrast of the young man and his father on one side and the adverse situation of those not as successful, the "people," the "others" of the poem, who "envy" the youngster of his education and ill-gotten wealth.

The irony in the poem equally lies in the fact that the persona himself re-echoes the criticisms made against his son and his corrupt ways: "but his pens sign fat cheques" (line 7). He refers to the careful process of looting the people's resources with the aid of the "pen" rather than through some overt methods that can be easily punished. The lexico-phonological ambiguity is also present in the last line: "hence my sons an elect." The written shape suggests at least two phonological realisations. The present graphic form of the line does not provide clues to any one appropriate interpretation. The possible readings are, first, "my sons, an elect" - in which case "sons" suggests that "elect" relates anaphorically to "selection" in the penultimate line, such that his sons form an elect (a select group). The addition of the comma will therefore give the line the status of two noun groups in apposition, with "an elect" psot-modifying "sons" or as an instance of compression in which the copula is omitted ("my sons are an elect"). The second reading 
will be "my son's an elect" in which case one son is involved and the apostrophe mark is added to "sons" to reveal a noun group + verb (equative copula) construction followed immediately by the second noun group acting as subject complement: "my son is an elect". (The present simple copula "is" is therefore in its contracted form in "my son's an elect".) The interpretation given to "elect" will remain the same in both cases but has greater force if his son alone forms "an elect" in the second interpretation. The difference in effect will therefore be one of degree. The masses (the "people," "others") are still the worse off for being neglected and exploited. The satiric tone is therefore biting irrespective of the reading given to the line since "an elect" is significant. It is the phrase that carries the social comment of the poem and the irony is in the exposure of a situation where few ("son" or "sons") are elitist, "selected" or separated from the many for luxury, education, wealth, etc. The many suffer - they can only complain. Hence the indifference of the speaker. The question we ask and the poet seems to intend that we ask is "Are the many justified in their envy?"' In the answer lies the comment.

It is possible to discuss the significance of this kind of graphological patterning in all the poems but similar instances as that discussed above abound in the other poems. It is possible, however, to give the same kind of dual interpretation to the homographic and homophonic "cant" in the poem "denied the lives of cats," reproduced below:

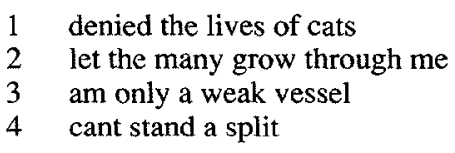

Line 4 is ambiguous because of the form of "cant." It can be interpreted as (1) "can't," as the contracted colloquial form of "cannot" in which mood is suggested (that of lack of tolerance); (2) "cant" can be interpreted as a verb meaning to "turn on the edge or corner; to tilt or toss suddenly" (Chambers Twentieth Century Dictionary), in which case it will properly collocate with "vessel" (ship) and "split" in lines 3 and 4: "am only a weak vessel / cant stand a split." This interpretation is possible if it is allowed that the poet is being equivocal (double-talking). This second "cant," because it is homophonic with the first, should be taken as a pun. This second reading may require the aid of juncture pauses between "cant" and "stand" and between "stand" and "a split" in line 4. If rewritten, with the commas provided, we have the following form: "am only a weak vessel : cant, stand, a split," thus providing a kind of rhythmic and semantic recreation of a weak vessel canting (tilting), standing (as it regains balance on being tossed by the waves) before it finally disintegrates for sinking (thus "a split").

The discussion of the two poems above is taken as representative of those in which Taban lo Liyong exhibits this deliberate use of the potentialities of graphological deviation to effect phonological and/or semantic ambiguities. In such ambiguities, therefore, a combination of phonological, structural and semantic clues rather than straightforward graphic ones are used as disambiguators. The interpretations we can consequently give to them are therefore not just merely conjectural but very likely and plausible. They are intented to be stylistically significant.

$\mathrm{V}$ - The emphasis on the graphological deviation patterns of Taban lo Liyong's Another Nigger Dead and their total significance is not intended to imply that they are the only significant deviations in this complex but deceptively simple collection of poems. It is possible, for instance, to highlight lexical collocational deviations of the types in "the filed man laughed and said" (p. 8) that reminds one of Dylan Thomas's "a grief ago." Deviant morphology is exploited in coinages involving unusual uses of the abstract noun 
suffix -ness to derive possible nouns from adjectives ("dunderheadedness") or even unlikely ones like "grabiousness" in the poem " $\mathrm{i}$ walked among men in america for a year without a human soul to solace me" (p. 54) - a poem that is reminiscent of E. E. Cummings's coinages. This discussion does not, however, rule out the fact that a complex interrelationship exists between all of them. The poet's peculiar use of the graphological mode is discussed because it is often the aspect neglected in typical literary discussions. It is, however, not unconnected with the thematic significance of the poems. The discussion of "there goes my son" above exemplifies this interrelationship. The attitude of the poet-persona in terms of poetic tone and the subject matter cannot be divorced from such a discussion of graphological usage. In that poem Taban decries the special opportunities open to only a few. But he instead allows a persona (one of the few) to re-echo the protests and frustrations of the many. The ambiguity shown to exist in the graphological form is used to underscore Taban's anger at the perverted admiration of the persona who indirectly or unwittingly emphasizes the atmosphere of poverty and lack of fulfillment among the masses. If the poetic persona is angry about or surprised at the "others" envy, is he justified? At this level of interpretation, the poet's own intended criticism of the ills of that society surfaces - i.e. once we start asking the questions. As revealed earlier, his satire is presented subtly but no less pungently. So here mode (medium) merges with field (subject-matter or context of the poem) and the tenor of discourse (the attitudes of the poet or the poetic persona and even the readers and their relationship with the context).

So after all is said, the final impression is that Tabal lo Liyong's poetic form is not just merely "curious" or incidental but reasonably deliberate and conscious. Its use of free verse, his use of lower-case letters, his neglect of punctuation marks, are intended to be significant, hence they are foregrounded. His is not deviation for deviation's sake but conscious art intended for the kind of purposes highlighted above, especially the ambiguity in graphic interpretation which the present typographic shape of the poems yields. A "normal" poetic form would have just been too normal and would not have yielded the kind of stylistic effect yielded by this apparently deviant form. However, since these deviations have become the rule rather than the exception in Another Nigger Dead, it would be appropriate to conclude that they acquire a degree of normalcy which is internal to the collection, a normalcy that puts them in a class of their own as poetry of direct utterance, an escape from the stylized ornamentation and restrictiveness of conventional marks.

Notes

1. This paper was presented in an earlier form to the 7th Ibadan Annual African Literature Conference, Univeristy of Ibadan, August 1982.

2. M. J. Gregory (1967): "Aspects of Varieties Differentiation," Journal of Linguistics, 3 :2, pp. 177-198.

3. E. A. Levenston (1979): "Speech and/or Writing: Lyric Poetry and the Media of Language," PTL, $4: 3$, pp. $451-474$.

4. Levenston, p. 457.

5. Okot p'Bitek (1972): "What Is Literature," Busara, 4:1, pp. 21-27; he emphasizes the importance of the "spoken word" as the vehicle in the communication between the "singer" and his "audience".

6. Kofi Awoonor: Guardians of the Sacred Word: Ewe Poetry, New York, Nok Publishers Ltd.

7. See Taban lo Liyong: Fixions, London, Heinemann (African Writers Series, 69), 1969, and Eating Chiefs, London, Heinemann (AWS, 74), 1970.

8. Adrian Roscoe (1977): Uhuru's Fire : African Literature East to South, Cambridge, Cambridge University Press, p. 114.

9. Prominent among the critics are E. D. Jones (1973): "Taban lo Liyong: Review," African Literature Today, 6, pp. 176-177; Ismael R. Mbise (1979): "The Struggle for Identify in Selected East African Literature and Art," Ph,D. dissertation, University of York, Toronto, May; Satoru Tsuchiya (1978): "Modern East African Literature : From Uhuru to Harambee," World Literature Today, 52:4, pp. 569-574; Timothy Wangusa (1973): "East African Poetry," $A L T, 6$, pp. 46-53; and Chris Wangjala (1971): "The Tabanic Genre," Busara, $3: 4$, pp. 23-29. 
10. Wangusa, p. 49.

11. Jones, p. 177.

12. Taban lo Liyong (1971): Frantz Fanon's Uneven Ribs, London, Heinemann (African Writers Series, 90). Quotations from poems in the collection will be from this edition.

13. Taban lo Liyong (1972): Another Nigger Dead, London, Heinemann (African Writers Series, 116). Subsequent references will be to this edition.

14. S. R. Levin (1963): "Deviation - Statistical and Determinate - in Poetic Language," Lingua, 12, pp. $276-290$.

15. Levin (1963): p. 278

16. William O. Hendricks (1974): "The Relation between Linguistics and Literary Studies," Poetics, 11, p. 7.

17. S. R. Levin (1965): "Internal and External Deviation in Poetry," Word, 12, p. 226.

18. Levin (1965): p. 227.

19. G. N. Leech (1969) : A Linguistic Guide to English Poetry, London, Longman, p. 47.

20. Roscoe, p. 130.

21. Taban lo Liyong has been quoted as saying, in his The Last Word, Nairobi, East African Publishing House, 1969 , about the process of his poetic composition, that :

I walked to my apartment, threw my suitcase on the bed and sat next to it. I then held my big head between my powerful hands. I squeezed it, and squeezed it hard, till it thought. When thought came, they poured like tropical rain: big and fast. I pulled out a pencil and wrote fast, capturing every drop of thought.

Quoted in Roscoe, 1977, p. 31. Roscoe has therefore aptly described this style as "a confessional strain, a stream-of-conscious-tell-it-all mode suggesting an honest mind's encounter with a myriad viewpoints" (p. 115).

22. The linguistic model used here is that of the British, neo-Firthian systemic type practised by M. A. K. Halliday, M. J. Gregory and others.

23. In the grammar, the nominal word group is made up of three main constituents: modifier (m), head (h) and qualifier (q). The head is the obligatory constituent ; the modifier and qualifier are optional.

24. E. E. Cummings (1972): Complete Poems, 1913-1962, New York, Harcourt, Brace and Jovanovich, p. 554.

25. Wanjala: "The Tabanic Genre," p. 27. 